\title{
Cardiac Computed Tomography versus 3D-Transesophageal Echocardiography in Preprocedural Planning of Left Atrial Appendage Closure
}

Jaroslaw Heinrich ${ }^{1}$, Baravan Al-Kassou ${ }^{2}$, Heyder Omran ${ }^{3 *}$

${ }^{1}$ Bundeswehrzentralkrankenhaus Koblenz, Klinik I, Rübenacher Str. 170, 56072 Koblenz, Germany

${ }^{2}$ Medizinische Klinik und Poliklinik II, Universitätsklinikum Bonn, Venusberg-Campus 1, 53127 Bonn, Germany

${ }^{3}$ GFO Kliniken Bonn, Robert-Koch-Str. 1, 53115 Bonn, Germany

*Corresponding Author: Heyder Omran, GFO Kliniken Bonn, Robert-Koch-Str. 1, 53115 Bonn, Germany

Received Date: February 16, 2021; Accepted Date: March 11, 2021; Published Date: March 18, 2021

Citation: Jaroslaw Heinrich, Baravan Al-Kassou, Heyder Omran., (2021) Cardiac Computed Tomography versus 3D-Transesophageal Echocardiography in Preprocedural Planning of Left Atrial Appendage Closure. J. Clinical Cardiology and Cardiovascular Interventions, 4(6); Doi: $10.31579 / 2641-0419 / 145$

Copyright: (C) 2021 Heyder Omran, This is an open-access article distributed under the terms of the Creative Commons Attribution License, which permits unrestricted use, distribution, and reproduction in any medium, provided the original author and source are credited.

\begin{abstract}
Aim: Preprocedural imaging of the left atrial appendage (LAA) plays a crucial role in the process of LAA closure (LAAC). This study aimed to compare the influence of preprocedural planning of the LAAC with 3Dtransesophageal echocardiography (TEE) and cardiac computed tomography (CCT) versus 3D-TEE alone in patients who underwent LAAC with an Amplatzer Cardiac Plug or Amulet.

Materials and Methods: In a retrospective study, 176 patients received a preprocedural 3D-TEE and CCT and 167 patients a 3D-TEE only. Both groups had similar patient characteristics and indications for LAAC.

Results: There was no difference in terms of procedural success, procedure time, amount of contrast medium, fluoroscopy time, or radiation dose. Patients with CCT/3D-TEE had a longer hospital stay on average. Besides, there was a different incidence of renal diseases (49\% for 3D-TEE versus $27 \%$ for CCT/3D-TEE; $p<0.001$ ). The number of periprocedural adverse events was comparable. A device-related thrombus occurred three times in each group, and the peri-device leaks reported were similar.

Conclusion: A preprocedural CCT does not decrease major adverse events or improve outcome in patients undergoing LAAC.

Keywords: left atrial appendage closure; imaging modalities; cardiac computed tomography; transesophageal echocardiography; 3D transesophageal echocardiography
\end{abstract}

\section{Introduction}

Atrial fibrillation (AF) occurs in $1-2 \%$ of the population in western countries and has a higher prevalence in men and older subjects [1-3]. One of the most feared complications in patients with $\mathrm{AF}$ is thromboembolism [5]. Approximately $90 \%$ of all thrombi develop in the left atrial appendage (LAA) [4]. Therefore, it is not surprising that one in five strokes are caused by AF, and $80 \%$ of all strokes are of an ischemic etiology $[6,7,37]$.

In order to reduce the risk of strokes, oral anticoagulation with vitamin $\mathrm{K}$ antagonists (VKA) and new oral anticoagulants (NOACs) is a validated treatment $[8,9]$. Nonetheless, the use of oral anticoagulants (OACs) increases the risk of intracerebral and gastrointestinal bleeding [10-13]. Hence the use of the clinical scores, HAS-BLED and $\mathrm{CHA}_{2} \mathrm{DS}_{2}-\mathrm{VASc}$ score, help to balance the risk of strokes and major bleeding in patients with $\mathrm{AF}[14,15]$. Interventional closure of the LAA (LAAC) has been shown to be a valid alternative in patients with a contraindication against OACs $[16,17]$.

In the process of device implantation, planning and preprocedural imaging of the LAA is important.

There are currently two main imaging techniques to assess the LAA before LAAC:

Two-dimensional and three-dimensional (2D/3D)-transesophageal echocardiography (TEE) and cardiac computed tomography (CCT) [19].

$3 \mathrm{D}-\mathrm{TEE}$ is used generally for preprocedural planning and periprocedural intervention, to assess the geometry and size of the LAA and, at most, predict the correct device size [22-24]. It was shown to be superior to 2DTEE with regard to determining the LAA orifice area/size [24] and LAA 
occluder size [28]. One study postulated that LAA measurements obtained using real time 3D-TEE showed smaller values than those obtained with CCT [26] and another study found that 3D-TEE was inferior at defining the ostial perimeter and correct occluder size, as compared to CCT [27].

Nonetheless, 3D-TEE imaging allows the LAA to be well visualized before, during, and after the procedure [25].

Cardiac computed tomography (CCT) has been shown as a valid imaging modality to detect LAA thrombi [23], to describe the LAA morphology, and to calculate the predicted device size for the LAAC [20, 21]. However, CCT imaging of the LAA is associated with nephrotoxic risks from the intravenous contrast dye and radiation exposure [29]. Importantly, it was demonstrated that there is a better agreement of the actual diameters and perimeters compared with device diameters and perimeters, i.e. the device fits the dimensions better, for CCT compared to TEE [27, 30].

There are only a few studies that have examined the influence of preprocedural CCT and TEE versus TEE alone, in terms of procedure time, contrast use, correct device size and number of devices utilized. Two small studies have shown a significant reduction in procedure time and anesthesia time, a greater accuracy in device selection, and an absence of peri-device leaks in the group that received a preprocedural CCT [30, 31]. However, data on the influence of preprocedural CCT, concerning the periprocedural and long-term transesophageal echocardiographic outcome, are scarce.

The aim of our study was to compare the influence of preprocedural planning of the LAAC with 3D-TEE and CCT versus 3D-TEE alone, in patients who underwent LAAC with the Amplatzer Cardiac Plug (ACP) and Amulet device, to assess the periprocedural outcome and the longterm transesophageal echocardiographic outcome.

\section{Materials and Methods}

\subsection{Study Population}

In this retrospective study, we collected data from a total of 343 consecutive patients with $\mathrm{AF}$ and contraindication to effective OAC, who underwent a LAAC procedure with the ACP or AMPLATZER Amulet between September 2009 and December 2019, were appraised and analyzed [45]. The main focus of this study was to compare the impact of CCT versus TEE in terms of preprocedural planning and the clinical outcome of the LAAC: Group 1 had 3D-TEE and CCT $(n=176)$ versus Group 2 had 3D-TEE $(n=167)$ alone. In both groups, clinical characteristics and patient demographics as well as procedural performance, clinical outcome, and echocardiographic follow-up data were collected and statistically contrasted with each other.

\subsection{Preprocedural imaging}

\subsubsection{D-TEE}

The 3D-TEE was performed by using a GE Vivid E9 BT12 cardiovascular ultrasound system, at least 24 hours prior to the LAAC procedure. The main aim of the imaging was to exclude intracardial thrombus and to assess three-dimensional images of the LAA. By using the zoom mode from pyramidal data sets, LAA images were recorded by using one-beat acquisition at end-expiration with a resolution of 18 to 21 beats per second [32]. The objective of images obtained was to display the landing zone (LZ) to its full extent and to create a three-dimensional visualization of the LAA by slicing the pyramidal data sets along $\mathrm{x}, \mathrm{y}$, and $\mathrm{z}$ axes [32].

The imaging data was subsequently analyzed with the GE EchoPAC BT12 software using the 12-channel multislice mode, thus helping to display the LAA in a three-dimensional way. With the help of a crosssectional view, the perimeter, area, and maximal/ minimal diameter (D max, D min) of the LZ was measured, which is defined as a level plane from the left circumplex coronary artery to the roof of the LAA, approximately $10 \mathrm{~mm}$ inward from the peak of the rim that separates the LAA and the left superior pulmonary vein [32]. The mean diameter (D average) was derived from the perimeter (Dper) using the formula: Dper $=\mathrm{P} / \pi$.

Further details on the use of 3D-TEE images were previously described $[23,32]$.

\subsubsection{Cardiac CT (CCT)}

CCT scans were performed by Siemens Somatom Definition Flash (Siemens Healthcare CT Systems, Forchheim, Germany), a dual source 256-slice CT scanner, at least 24 hours prior to the LAAC procedure and usually on the same day as the TEE. The first preprocedural images were generated in September 2012.

The focus for the evaluation of the CCT images was detecting/excluding a thrombus in the LAA, assessing the size of the landing zone, and therefore, predicting the size of the device needed, and finally, identifying the LAA anatomy [37]. Imeron ${ }^{\circledR} 350 \quad(350 \mathrm{mg}$ iodine $/ \mathrm{ml})$ was intravenously administered as the contrast agent, with an average of 40 $100 \mathrm{ml}$ given per scan depending on the patient characteristics, most notably their weight and renal function [40].

The images were made with a prospective ECG gating technique that considers the R-R-interval [40]. The recorded images of the LAA were subsequently analyzed by 3 mensioTM, an LAA workflow assistant (Pie Medical Imaging, Maastricht, The Netherlands).

By using the trans-axial images, the circumflex artery, the pulmonary vein ridge, and the LAA ostium were displayed [27]. With the help of the multiplanar reconstruction (MPR) view, a plane from the level of the circumflex artery to $10 \mathrm{~mm}$ below the pulmonary vein ridge was drawn, which defined the landing zone. Furthermore, the landing zone was displayed in a cross-sectional view and the diameter calculated from the perimeter was assigned as described above.

Elaborate descriptions of the preprocedural CCT were published previously [27, 37, 38, 39, 40].

\subsection{Implantation of the Device}

The LAAC implantation process was performed in all patients under general anesthetic. The execution of the implantation procedure was made by using contrast angiography and periprocedural TEE, using the GE Vivid E9 BT12 [18].

The device selection was made based on the measurements of the maximum diameter of the LZ, as described above, and contrast angiography, as recommended by the manufacturer's instructions (AMPLATZER Cardiac Plug, AMPLATZER Amulet, Left Atrial Appendage Occluder Instructions for Use, St. Jude Medical, Minnesota, USA) [18].

\subsection{Angiographic Assessment of the Implantation Procedure}

The time from the beginning of the procedure until the extubation of the patients, the fluoroscopy time in minutes, the radiation dose $\left(\mathrm{cGy}^{*} \mathrm{~cm}^{2}\right)$, and the amount of contrast dye given in milliliters were registered by using the DAVID hemodynamic software (Metek, Germany) [18]. Beyond this, procedural success as well as device resizing were assessed.

\subsection{Periprocedural Adverse Events}

With respect to the VARC (Valve Academic Research Consortium) criteria and the Munich consensus document [35, 36], major adverse events (MAEs) included periprocedural mortality, strokes, systemic 
embolism, myocardial infarction, cardiac tamponade, major bleeding, device embolization, and need for surgery. Furthermore, other adverse events such as TIA, air embolism, vascular complications, as well as acute kidney injuries were assessed and evaluated.

The primary endpoint was defined as the clinical outcome (MAEs and other adverse events) of the LAAC. The secondary endpoint focused on the device-related outcome (device-related thrombus and peri-device leakage) in the echocardiographic follow-up of the patients.

\subsection{Echocardiographic Follow-Up of the Patients}

Almost every patient received one to three follow-up TEEs in a period from one month to two years in order to track the position of the device, thrombus formation, and peri-device leaks using Echo color Doppler and multiple TEE views, as previously suggested [36].

Leaks were defined, with regard to the width of the color jet-flow, as a minor leak $(<1 \mathrm{~mm})$, moderate leak $(1-3 \mathrm{~mm})$, major leak $(>3 \mathrm{~mm})$, or severe leak (multiple jets or free flow) [18].

\subsection{Statistical analysis}

Continuous variables are described as the mean \pm standard deviation (SD) and were analyzed via paired or unpaired Student's $t$-tests, if distribution was normal.

Categorical variables are described as absolute numbers and percentages. The Chi-square test was used to compare categorical variables.

Statistical significance was considered as a two-tailed probability value $<0.05$. Statistical analyses were performed with SPSS version 26 (IBM Corp., Armonk, NY, USA).

\section{Results}

\subsection{Patient characteristics}

\begin{tabular}{|c|c|c|c|c|}
\hline & $\begin{array}{c}\text { Overall Cohort } \\
(\mathrm{n}=343)\end{array}$ & $\begin{array}{c}\text { CT-guided LAAC } \\
(\mathrm{n}=176)\end{array}$ & $\begin{array}{c}\text { 3D-TEE-guided LAAC } \\
(\mathrm{n}=167)\end{array}$ & p value \\
\hline Age (years) & $75.98 \pm 7.27$ & $76.1 \pm 7.04$ & $75.94 \pm 7.52$ & 0.95 \\
\hline Age $\geq 75$ (years) & $213(62)$ & $114(65)$ & $99(59)$ & 0.29 \\
\hline Male (n) & $194(57)$ & $101(57)$ & $93(56)$ & 0.75 \\
\hline Body mass index $\left(\mathrm{kg} / \mathrm{m}^{2}\right)$ & $27.29 \pm 5.56$ & $27.41 \pm 5.41$ & $27.17 \pm 5.74$ & 0.36 \\
\hline $\mathrm{CHA}_{2} \mathrm{DS}_{2} \mathrm{VASC}$ score & $4.65 \pm 1.55$ & $4.72 \pm 1.62$ & $4.57 \pm 1.48$ & 0.21 \\
\hline HASBLED score & $4.01 \pm 1.06$ & $3.9 \pm 1.01$ & $4.13 \pm 1.1$ & 0.05 \\
\hline Atrial fibrillation (n) & 343 & 176 & 167 & 0.5 \\
\hline Paroxysmal & $127(37)$ & $69(39)$ & $58(35)$ & 0.39 \\
\hline Persistent & $52(15)$ & $26(15)$ & $26(16)$ & 0.84 \\
\hline Permanent AF & $163(48)$ & $81(46)$ & $83(50)$ & 0.50 \\
\hline \multicolumn{5}{|l|}{ Clinical features } \\
\hline Coronary artery disease $(n)$ & $151(44)$ & $79(45)$ & $72(43)$ & 0.74 \\
\hline Myocardial infarction & $55(16)$ & $25(14)$ & $30(18)$ & 0.34 \\
\hline PCI & $86(25)$ & $45(26)$ & $41(25)$ & 0.83 \\
\hline CABG & $39(11)$ & $22(13)$ & $17(10)$ & 0.5 \\
\hline Heart failure (n) & $82(24)$ & $40(23)$ & $42(25)$ & 0.6 \\
\hline Arterial hypertension (n) & $309(90)$ & $156(89)$ & $153(92)$ & 0.36 \\
\hline Diabetes mellitus (n) & $87(25)$ & $41(23)$ & $46(28)$ & 0.37 \\
\hline Hyperlipidemia (n) & $146(43)$ & $79(45)$ & $67(40)$ & 0.37 \\
\hline
\end{tabular}

343 consecutive patients who underwent LAAC, from September 2009 to December 2019, were enrolled in this study. 176 patients received a preprocedural CT and a 3D-TEE, 167 patients received exclusively a preprocedural 3D-TEE. Baseline patient characteristics are shown in (Table 1).

Most patient characteristics did not differ significantly between the two groups. However, there was a significant difference in the HASBLED score with $4.1 \pm 1.1$ for the 3D-TEE group and $3.9 \pm 1.01$ for the CT/3DTEE group $(\mathrm{p}=0.05)$. Whereas, the CHA2DS2-VASc score was similar between the groups $(4.57 \pm 1.48$ for $3 \mathrm{D}$-TEE versus $4.72 \pm 1.62$ for CT/3D-TEE; $p=0.21$ ).

Medications were well-balanced between the groups. However, 122 (73\%) patients of the 3D-TEE group and $109(62 \%)$ patients of the $\mathrm{CT} / 3 \mathrm{D}-\mathrm{TEE}$ group $(\mathrm{p}=0.03)$ received diuretics. The corresponding values for ACE inhibitors were 48 (29\%) patients for the 3D-TEE and 71 $(40 \%)$ patients for the CT/3D-TEE $(\mathrm{p}=0.02)$ group.

Furthermore, there were more smokers in the 3D-TEE guided group $(\mathrm{n}=$ $56(34 \%)$ for 3D-TEE versus $n=37(21 \%)$ for CT/3D-TEE, $p=0.01)$.

Not surprisingly, the 3D-TEE guided group had a higher prevalence of renal disease $(n=81(49 \%)$ for $3 D-T E E$ versus $n=47(27 \%)$ for CT/3DTEE; $\mathrm{p}<0.001)$. This finding was also reflected by the creatinine levels $(1.59 \pm 1.0 \mathrm{mg} / \mathrm{dl}$ for $3 \mathrm{D}$-TEE versus $1.21 \pm 0.88 \mathrm{mg} / \mathrm{dl}$ for CT/3D-TEE; $\mathrm{p}<0.001)$.

\subsection{Indications for $L A A C$}

In both groups, more than a half of all patients has had a previous major bleeding event $(n=93(56 \%)$ for 3D-TEE versus $n=89(51 \%)$ for CT/3DTEE; $\mathrm{p}=0.34$ ), which was the most important indication for LAAC (listed in Table 2) in this study. Although, there were significantly more patients in the 3D-TEE guided group with previous gastrointestinal bleeding $(\mathrm{n}=$ $55(33 \%)$ for $3 \mathrm{D}-\mathrm{TEE}$ versus $\mathrm{n}=41(23 \%)$ for CT/3D-TEE; $p=0.047)$. 


\begin{tabular}{|c|c|c|c|c|}
\hline Creatinine (mg/dl) & $1.4 \pm 0.96$ & $1.21 \pm 0.88$ & $1.59 \pm 1.0$ & 0.00 \\
\hline Quick (\%) & $87.51 \pm 24.79$ & $87.18 \pm 26.36$ & $87.85 \pm 23.12$ & 0.83 \\
\hline INR & $1.43 \pm 5.24$ & $1.72 \pm 7.31$ & $1.12 \pm 0.26$ & 0.83 \\
\hline PTT (sec) & $28.12 \pm 8.68$ & $28.0 \pm 6.21$ & $28.23 \pm 10.72$ & 0.75 \\
\hline Nikotin (n) & $93(27)$ & $37(21)$ & $56(34)$ & 0.01 \\
\hline \multicolumn{5}{|l|}{ Medication before LAA occlusion } \\
\hline Clopidogrel (n) & $42(12)$ & $23(13)$ & $19(11)$ & 0.63 \\
\hline Vitamin K antagonist (n) & $26(8)$ & $16(9)$ & $10(6)$ & 0.28 \\
\hline Noval oral anticoagulant $(\mathrm{n})$ & $89(26)$ & $48(27)$ & $41(25)$ & 0.57 \\
\hline Low molecular weight heparin (n) & $71(21)$ & $31(18)$ & $40(24)$ & 0.15 \\
\hline Beta blocker (n) & $260(76)$ & $129(73)$ & $131(78)$ & 0.27 \\
\hline Statin (n) & $163(48)$ & $90(51)$ & $73(44)$ & 0.17 \\
\hline Diuretic (n) & $231(67)$ & $109(62)$ & $122(73)$ & 0.03 \\
\hline ACE inhibitor (n) & $119(35)$ & $71(40)$ & $48(29)$ & 0.02 \\
\hline \multicolumn{5}{|l|}{ Risk factors for bleeding } \\
\hline Previous stroke $(\mathrm{n})$ & $111(32)$ & $65(37)$ & $46(28)$ & 0.63 \\
\hline TIA (n) & $26(8)$ & $14(8)$ & $12(7)$ & 0.79 \\
\hline Prior major bleeding $(\mathrm{n})$ & $182(53)$ & $89(51)$ & $93(56)$ & 0.34 \\
\hline Renal disease (n) & $128(37)$ & $47(27)$ & $81(49)$ & 0.00 \\
\hline Liver disease (n) & $13(4)$ & $6(3)$ & $7(4)$ & 0.70 \\
\hline Labile INR (n) & $7(2)$ & $1(1)$ & $6(4)$ & 0.05 \\
\hline Age $>65$ (n) & $316(92)$ & $163(93)$ & $153(92)$ & 0.73 \\
\hline
\end{tabular}

PCI: percutaneous coronary intervention; $\boldsymbol{C A B G}$ : coronary artery bypass graft; INR: international normalized ratio; PTT: prothrombin time; $\boldsymbol{A C E}$ : angiostensin converting enzyme; TIA: transitory ischemic attack;

Table 1. Patient Characteristics

\begin{tabular}{|l|c|c|c|c|}
\hline & $\begin{array}{c}\text { Overall Cohort } \\
(\mathrm{n}=343)\end{array}$ & $\begin{array}{c}\text { CT-guided } \\
\text { LAAC } \\
(\mathrm{n}=176)\end{array}$ & $\begin{array}{c}\text { 3D-TEE- } \\
\text { guided LAAC } \\
(\mathrm{n}=167)\end{array}$ & p value \\
\hline Previous major bleeding (n) & $182(53)$ & $89(51)$ & $93(56)$ & 0.34 \\
\hline \multicolumn{1}{|l|}{ Intracranial bleeding } & $62(18)$ & $38(22)$ & $24(14)$ & 0.082 \\
\hline $\begin{array}{l}\text { Gastrointestinal } \\
\text { bleeding }\end{array}$ & $96(28)$ & $41(23)$ & $55(33)$ & 0.047 \\
\hline Other & $27(8)$ & $13(7)$ & $14(8)$ & 0.73 \\
\hline Previous minor bleeding (n) & $132(38)$ & $68(39)$ & $64(38)$ & 0.95 \\
\hline $\begin{array}{l}\text { Gastrointestinal } \\
\text { bleeding }\end{array}$ & $63(18)$ & $31(18)$ & $32(19)$ & 0.71 \\
\hline Hematoma & $24(7)$ & $13(7)$ & $11(7)$ & 0.77 \\
\hline Other & $56(16)$ & $28(16)$ & $28(17)$ & 0.83 \\
\hline Renal or hepatic disease (n) & $14(4)$ & $5(3)$ & $9(5)$ & 0.24 \\
\hline $\begin{array}{l}\text { High risk of falls or prior falls } \\
\text { (n) }\end{array}$ & $23(7)$ & $8(5)$ & $15(9)$ & 0.10 \\
\hline $\begin{array}{l}\text { Physician/patient refusal of oral } \\
\text { anticoagulation (n) }\end{array}$ & $4(1)$ & $3(2)$ & $1(1)$ & 0.34 \\
\hline For some patients more than 1 indication was reported & & & \\
\hline
\end{tabular}

Table 2. Indications for left atrial appendage occlusion

\begin{tabular}{|c|c|c|c|c|}
\hline & $\begin{array}{l}\text { Overall Cohort } \\
(n=343)\end{array}$ & $\begin{array}{l}\text { CT-guided LAAC } \\
\qquad(\mathrm{n}=176)\end{array}$ & $\begin{array}{l}\text { 3D-TEE-guided } \\
\text { LAAC } \\
(\mathrm{n}=167)\end{array}$ & p value \\
\hline Procedural success (n) & $339(99)$ & $175(99)$ & $164(98)$ & 0.29 \\
\hline Procedure time (min) & $78.59 \pm 27.96$ & $78.19 \pm 26.57$ & $79.00 \pm 29.39$ & 0.98 \\
\hline Contrast medium (ml) & $115.94 \pm 63.66$ & $119.03 \pm 59.09$ & $112.67 \pm 68.17$ & 0.99 \\
\hline Fluoroscopy time (min) & $11.17 \pm 6.13$ & $10.71 \pm 5.63$ & $11.63 \pm 6.59$ & 0.31 \\
\hline
\end{tabular}




\begin{tabular}{|l|c|c|c|c|}
\hline Radiation dose (cGy*cm2) & $3060.72 \pm 2729.19$ & $2974.79 \pm 2432.4$ & $3148.19 \pm 3006.27$ & 0.73 \\
\hline More than 1 device tried (n) & $22(6)$ & $8(5)$ & $14(8)$ & 0.15 \\
\hline Larger Device finally implanted & $5(1)$ & $3(2)$ & $2(1)$ & 0.70 \\
\hline Smaller Device finally implanted & $15(4)$ & $5(3)$ & $10(6)$ & 0.15 \\
\hline Devices utilized (n) & $1.08 \pm 0.37$ & $1.06 \pm 0.37$ & $1.1 \pm 0.37$ & 0.17 \\
\hline Hospital stay (days) & $6.76 \pm 4.7$ & $6.98 \pm 0.36$ & $6.43 \pm 0.35$ & 0.01 \\
\hline
\end{tabular}

Table 3. Procedural data

\begin{tabular}{|c|c|c|c|c|}
\hline & $\begin{array}{c}\text { Overall Cohort } \\
(n=343)\end{array}$ & $\begin{array}{l}\text { CT-guided LAAC } \\
\qquad(\mathrm{n}=176)\end{array}$ & $\begin{array}{c}\text { 3D-TEE-guided } \\
\text { LAAC } \\
(\mathrm{n}=167)\end{array}$ & p value \\
\hline \multicolumn{5}{|l|}{ Major adverse events } \\
\hline Death (n) & $3(1)$ & $1(1)$ & $2(1)$ & 0.53 \\
\hline Stroke (n) & $1(0.3)$ & 0 & $1(0.6)$ & 0.3 \\
\hline Systemic embolism (n) & 0 & 0 & 0 & 1 \\
\hline Myocardial infarction (n) & 0 & 0 & 0 & 1 \\
\hline Cardiac tamponade $(\mathrm{n})$ & $3(1)$ & $2(1)$ & $1(0.6)$ & 0.59 \\
\hline Major bleeding (n) & $9(3)$ & $4(2)$ & $5(3)$ & 0.68 \\
\hline Intracranial bleeding & $1(0.3)$ & $1(1)$ & 0 & 0.33 \\
\hline Gastrointestinal & $2(0.6)$ & 0 & $3(2)$ & 0.08 \\
\hline $\begin{array}{l}\text { Epistaxis required blood } \\
\text { transfusion due to M. Osler }\end{array}$ & $1(0.3)$ & 0 & $1(0.6)$ & 0.32 \\
\hline Device embolization requiring surgery $(\mathrm{n})$ & $1(0.3)$ & 0 & $1(0.6)$ & 0.3 \\
\hline Device embolization snared (n) & 0 & 0 & 0 & 1 \\
\hline Need for surgery $(\mathrm{n})$ & $1(0.3)$ & 0 & $1(0.6)$ & 0.3 \\
\hline Total & $22(6)$ & $8(5)$ & $14(8)$ & 0.15 \\
\hline \multicolumn{5}{|l|}{ Other adverse events } \\
\hline TIA (n) & 0 & 0 & 0 & 1 \\
\hline $\begin{array}{l}\text { Air embolism (transient ST elevation and/or } \\
\text { chest pain) (n) }\end{array}$ & $1(0.3)$ & $1(1)$ & 0 & 0.33 \\
\hline Vascular complication (n) & $9(3)$ & $6(3)$ & $3(2)$ & 0.83 \\
\hline Femoral artery pseudoaneurysm & $6(2)$ & $4(2)$ & $2(1)$ & 0.45 \\
\hline Arteriovenous fistula & $3(1)$ & $2(1)$ & $1(0.6)$ & 0.59 \\
\hline Acute kidney injury (n) & $4(1)$ & $2(1)$ & $2(1)$ & 0.96 \\
\hline Fever of unknown origin (n) & $4(1)$ & $2(1)$ & $2(2)$ & 0.96 \\
\hline Total (n) & $26(8)$ & $17(10)$ & $9(5)$ & 0.13 \\
\hline
\end{tabular}

Table 4. Periprocedural adverse events

\subsection{Data}

339 of 343 LAAC procedures were successful, resulting in an overall success rate of $99 \%$. There was no significant difference for the success rate between the $\mathrm{CT}$ and 3D-TEE guided group $(\mathrm{n}=175(99 \%)$ for $\mathrm{CT} / 3 \mathrm{D}-\mathrm{TEE}$ versus $\mathrm{n}=164(98 \%)$ for $3 \mathrm{D}-\mathrm{TEE} ; \mathrm{p}=0.29)$.

The failed attempt at device implantation in the CT/3D-TEE guided group was due to a complicated anatomy of the LAA. In the 3D-TEE guided group, the reasons for the failure of the LAAC procedure were:

1. periprocedural death due to pulseless electrical activity,

\section{A complicated LAA anatomy, and}

3. An unsuccessful puncture of the atrial septum as a result of a teflon patch of the interatrial septum after cardiac surgery.

There was no significant difference for both groups concerning the procedure time, the amount of contrast medium used, the fluoroscopy time, or the radiation dose.
Importantly, there was also no significant difference in the number of devices that needed to be resized in the 3D-TEE guided group $(\mathrm{n}=14$ $(8 \%)$ versus $\mathrm{n}=8(5 \%)$ for CT/3D-TEE $(\mathrm{p}=0.15)$.

However, patients who received a CCT before LAAC stayed longer in the hospital than those patients without CCT $(6.43 \pm 0.35$ days for 3D-TEE versus $6.98 \pm 0.36$ days for CT/3D-TEE; $\mathrm{p}=0.01)$.

\subsection{Adverse events}

Twenty-two $(6 \%)$ of 343 consecutive patients who underwent LAAC suffered from a major adverse event. Of these, 14 patients $(8 \%)$ from the 3D-TEE guided group and 8 patients $(5 \%)$ from the CT/3D-TEE guided group were affected $(\mathrm{p}=0.15)$.

Three accumulated deaths were observed in both groups. One patient of the CT/3D-TEE guided group died after a cardiac tamponade following LAAC and a volume deficiency shock after cardiopulmonary resuscitation. Of the two reported deaths in the 3D-TEE group, one was caused by a pulseless electrical activity during the LAAC, and the other patient had a device dislocation after the intervention and died of a bleeding complication following the operation to remove the device. 
There was no statistical difference between the two groups regarding deaths $(\mathrm{p}=0.53)$.

Major bleeding after LAAC appeared in five cases (3\%) in the 3D-TEE group and four cases $(2 \%)$ in the CT/3D-TEE group with no statistical difference $(\mathrm{p}=0.68)$. Those events were divided into three $(2 \%)$ gastrointestinal bleedings, one $(0.6 \%)$ epistaxis due to M. Osler and one $(0.6 \%)$ inguinal bleeding after puncture in the 3D-TEE group. In the $\mathrm{CT} / 3 \mathrm{D}-\mathrm{TEE}$ group, there was one $(0.6 \%)$ intracranial bleeding, one $(0.6 \%)$ hemorrhagic pericardial tamponade requiring one erythrocyte concentrate, one $(0.6 \%)$ epistaxis, and one $(0.6 \%)$ traumatic hard palate bleeding, that were defined as major bleeding events.

Two cases of acute kidney injuries were reported in each of the groups after LAAC, with no significant difference $(\mathrm{p}=0.96)$.

\begin{tabular}{|c|c|c|c|c|}
\hline & $\begin{array}{c}\text { Overall Cohort } \\
(\mathrm{n}=288)\end{array}$ & $\begin{array}{c}\text { CT-guided LAAC } \\
(\mathrm{n}=154)\end{array}$ & $\begin{array}{c}\text { 3D-TEE-guided LAAC } \\
(\mathrm{n}=134)\end{array}$ & p value \\
\hline Device-related thrombus (n) & $6(2)$ & $3(2)$ & $3(2)$ & 0.86 \\
\hline Peridevice leakage (n) & $36(10)$ & $21(14)$ & $15(11)$ & 0.53 \\
\hline Severe leaks & 0 & 0 & 0 & 1 \\
\hline Major leak & 0 & 0 & 0 & 1 \\
\hline Moderate leak & $1(0.3)$ & $1(0.6)$ & $15(11)$ & 0.35 \\
\hline Minor leak & $35(10)$ & $20(13)$ & 0.64 \\
\hline
\end{tabular}

Table 5: Prevalence and severity of peridevice leaks at transesophageal echocardiographic follow up

\section{Discussion}

LAAC is an established alternative to oral anticoagulation treatment in patients with $\mathrm{AF}$ and contraindications against OACs [46]. In order to achieve an effective procedure for each patient, in terms of present and long-term implantation success and a reduction of adverse events, we retrospectively investigated the influence of CCT as an additional preprocedural imaging modality besides the commonly utilized 3D-TEE.

\subsection{Outcome}

In comparison to the ACP multicenter registry [41], we had a similar overall procedural success rate in our study $(97.3 \%$ vs $98.8 \%)$ and periprocedural MAE rate (5\% vs. $6.4 \%)$. In concordance with our results, Koskinas et al. [42] reported MAEs of $5.8 \%$ in 500 consecutive patients.

An important finding of our study was that we did not find a difference in the procedural success rate between patients who underwent a CCTplanned strategy for LAAC and patients with a 3D-TEE-only guided strategy (99\% versus 98\%). Furthermore, we did not detect higher firstdevice accuracy in the CCT/3D-TEE group (94.9\%) than in the 3D-TEE group $(91 \%)$. In addition, the overall number of devices used was not different between the CCT/3D-TEE and 3D-TEE only groups $(1.06 \pm 0.37$ for CCT vs. $1.1 \pm 0.37$ for 3D-TEE; $p=0.17$ ).

In contrast, a much smaller study by Eng et al. [44], which randomized 24 patients to undergo LAAC using either 2D-TEE or 3D-CT for implanting WATCHMAN ${ }^{\mathrm{TM}}$ devices, found a higher procedural success rate in the 3D-CT than in the 2D-TEE group (100\% vs 92\%). Furthermore, this study showed that the accuracy for first device selection and the number of devices used was significantly better for 3D-CT than $2 \mathrm{D}-\mathrm{TEE}(92 \%$ vs. $27 \%$ and $1.33 \pm 0.7$ vs. $2.5 \pm 1.2$, respectively). The difference between our findings and the study by Eng et al. may be explained by the smaller study group, different device used, and by the use of 2D-TEE, which is much less accurate than 3D-TEE [28, 32].

Dutcher et al. [31] compared a CT-guided and TEE-guided strategy in 154 consecutive patients (CT $n=76$ vs. TEE $n=78$ ) who received the WATCHMAN device. The authors of this study reported a significantly better accuracy rate concerning first device selection in the CT group with $86.7 \%$ for the CT-guided group vs $75.6 \%$ for the TEE group $(p=0.041)$.

\subsection{Echocardiographic follow up}

Of all the patients that underwent LAAC in this study, 288 (84\%) patients received at least one follow up 3D-TEE, at the earliest, one month after the procedure. Those were divided in 154 (53\%) patients for the CT/3DTEE guided group and $134(47 \%)$ patients for the 3D-TEE guided group $(\mathrm{p}=0.09)$.

In each group, three cases $(1.8 \%$ for 3D-TEE and $1.7 \%$ for CT/3D-TEE; $\mathrm{p}=0.86$ ) of device-related thrombi were detected (Table 5).

Furthermore, there were no significant differences in terms of minor leaks $(\mathrm{n}=15(11 \%)$ for $3 \mathrm{D}-\mathrm{TEE}$ versus $\mathrm{n}=20(13 \%)$ for $\mathrm{CT} / 3 \mathrm{D}-\mathrm{TEE} ; \mathrm{p}=0.64)$ or moderate leaks $(n=0$ for $3 \mathrm{D}$-TEE versus $\mathrm{n}=1(0.6 \%)$ for CT/3DTEE; $p=0.35)$. There were no major leaks in either group.
However, the difference between the groups was much smaller than in the study by Eng et al. [44]. Dutcher et al. also reported procedure times for the different groups. They observed significantly shorter procedure times in the CT group (33.6 min vs $46.5 \mathrm{~min}$ for TEE). In our study, the procedure time did not differ between the CCT/3D-TEE and 3D-TEE only groups.

We found in our study that fluoroscopy time and radiation doses did not differ between patients in the CCT/3D-TEE and in the 3D-TEE group. An interesting but small study of 24 patients receiving the WATCHMAN device by Obasare et al. [30] used a preprocedural CT to produce a latex model of the LAA using 3D printing $(\mathrm{n}=14)$ and compared that to preprocedural 2D-TEE imaging. The authors of this study reported of a significantly reduced procedure time $(70 \pm 20 \mathrm{vs}$. $107 \pm 53 \mathrm{~min}$ for $2 \mathrm{D}$ TEE, $\mathrm{p}=0.03)$ and fluoroscopy time $(11 \pm 4$ vs. $20 \pm 13 \mathrm{~min}$ for 2D-TEE, $\mathrm{p}=0.02$ ) for preprocedural CT. Unfortunately, there are some limitations concerning the comparisons of our study to Dutcher et al. and Obasare et $a l$. as they both used the WATCHMAN device, were much smaller, and applied different imaging concepts, including 2D-TEE, which is inferior to $3 \mathrm{D}$-TEE.

\subsection{Long-term echocardiographic outcome}

Landmesser et al. [43] showed in a large prospective Amplatzer Amulet observational study an adequate occlusion $(<3 \mathrm{~mm}$ jet$)$ of the appendage in $98.2 \%$ and detected a device thrombus in only $1.5 \%$ of 673 patients in the TEE follow-up, $67 \pm 23$ days after LAAC. Based on the definition of major leaks (jet-flow $>3 \mathrm{~mm}$ ) by the Munich consensus document [40], we did not detect any major leaks, although we had one $(0.6 \%)$ moderate and $35(10 \%)$ minor leaks in the first follow-up TEE, at the earliest one month after LAAC in 288 available patients. However, our device-related thrombus rate $(2.1 \%)$ was similar to the rate reported by Landmesser et al [43].

Importantly, in our study we could show that an absence of peri-device leaks was not statistically different between the 3D-TEE guided group and the CCT/3D-TEE group ( $88.8 \%$ vs. $86.4 \%)$. It is interesting that this finding is in concordance with the finding of Obasare et al., who reported an absence of peri-device leaks in $92 \%$ of patients who received a CTbased 3D-printed model. 


\subsection{Demographics}

Although patient characteristics were distributed predominantly equally in both groups, there were significantly more patients in the 3D-TEE guided group with a decreased renal function and a known renal disease. This is probably due to the selection bias of a non-randomized study, since the use of contrast agent during CCT can provoke acute renal failure or deteriorate renal function, in particular in patients with known renal disease, so it is likely that these patients were selected against for CCT.

Nevertheless, in our study, $27 \%$ of patients received a preprocedural CCT even though they had known renal disease. Interestingly, only two patients (1\%) suffered from an acute kidney injury during their hospital stay in the CCT/3D-TEE arm, which was also the case in the 3D-TEE only guided group (two cases (1\%)). All of these patients regained their original renal function during the hospital stay, under continued renalprotection measures. In this respect, it is important to note that in our study, patients in the CCT/3D-TEE arm did not need less contrast agent than in the 3D-TEE arm during the procedure $(120 \mathrm{ml}$ versus $112 \mathrm{ml})$. Hence, a CCT-guided strategy does not save contrast agent during the procedure.

Moreover, patients with an additional preprocedural CCT had a significantly longer hospital stay $(6.4 \pm 0.4$ days for $3 \mathrm{D}-\mathrm{TEE}$ alone versus $7 \pm 0.4$ days for CT/3D-TEE; $\mathrm{p}=0.01$ ) due to the fact that the CCT was performed one day before implantation of the device.

\section{Conclusion}

In conclusion, we did not find any difference between the preprocedural 3D-TEE and CCT/3D-TEE guided groups with respect to the primary endpoint, which was defined as the clinical outcome of the LAAC, or the secondary endpoint consisting of the echocardiographic follow-up.

In consideration of our results, we would suggest that a preprocedural CCT may be avoided before planning a LAAC, as we did not detect a decrease of MAEs or improved outcome. Moreover, the addition of a CCT leads to higher costs and a potentially longer hospital stay.

\section{Limitations}

The most important limitation of our study is its retrospective design. However, we only included consecutive patients. Furthermore, it was regarded as potentially difficult to randomize patients with advanced renal dysfunction to the CCT/3D-TEE group.

In our study, 3D-TEE was used for LAAC implantation, which was performed by experienced operators. Hence our results cannot be applied to centers that use only 2D-TEE for LAAC implantation guidance.

\section{Conflict of Interest Disclosures:}

The authors have no conflicts of interest to declare.

\section{References}

1. Stewart S, Hart CL, Hole DJ, McMurray JJ. Population prevalence, incidence, and predictors of atrial fibrillation in the Renfrew/Paisley study. Heart. 2001 Nov;86(5):516-521.

2. Heeringa J, van der Kuip DA, Hofman A, Kors JA, van Herpen G, Stricker BH, Stijnen T, Lip GY, Witteman JC. Prevalence, incidence and lifetime risk of atrial fibrillation: the Rotterdam study. Eur Heart J. 2006 Apr;27(8):949-953.

3. Kannel WB, Abbott RD, Savage DD, McNamara PM. Epidemiologic features of chronic atrial fibrillation: the Framingham study. N Engl J Med. 1982 Apr 29;306(17):10181022.
4. Al-Saady NM, Obel OA, Camm AJ. Left atrial appendage: structure, function, and role in thromboembolism. Heart. 1999 Nov;82(5):547-554.

5. Risk factors for stroke and efficacy of antithrombotic therapy in atrial fibrillation. Analysis of pooled data from five randomized controlled trials. Arch Intern Med. 1994 Jul 11;154(13):1449-1457.

6. Smith EE, Shobha N, Dai D, Olson DM, Reeves MJ, Saver JL, Hernandez AF, Peterson ED, Fonarow GC, Schwamm LH. A risk score for in-hospital death in patients admitted with ischemic or hemorrhagic stroke. J Am Heart Assoc. 2013 Jan 28;2(1):e005207.

7. Wolf PA, Abbott RD, Kannel WB. Atrial fibrillation as an independent risk factor for stroke: the Framingham Study. Stroke 1991;22:983-988.

8. Hart R, Pearce L, Aguilar M. Meta-analysis: antithrombotic therapy to prevent stroke in patients who have nonvalvular atrial fibrillation. Ann Intern Med 2007; 146:857-867

9. Yang E. A clinician's perspective: novel oral anticoagulants to reduce the risk of stroke in nonvalvular atrial fibrillation-full speed ahead or proceed with caution? Vasc Health Risk Manag 2014;10:507-522

10. Connolly, S.J., et al., Apixaban in patients with atrial fibrillation. N Engl J Med, 2011. 364(9): p. 806-817.

11. Connolly, S.J., et al., Dabigatran versus warfarin in patients with atrial fibrillation. N Engl J Med, 2009. 361(12): p. 11391151.

12. Granger, C.B., et al., Apixaban versus warfarin in patients with atrial fibrillation. N Engl J Med, 2011. 365(11): p. 981-992.

13. Patel, M.R., et al., Rivaroxaban versus warfarin in nonvalvular atrial fibrillation. N Engl J Med, 2011. 365(10): p. 883-891.

14. Roldán V, Marín F, Manzano-Fernández S, Gallego P, Vílchez JA, Valdés M, Vicente V, Lip GY. The HAS-BLED score has better prediction accuracy for major bleeding than CHADS2 or CHA2DS2-VASc scores in anticoagulated patients with atrial fibrillation. J Am Coll Cardiol. 2013 Dec 10;62(23):2199-2204.

15. Lip GY. Can we predict stroke in atrial fibrillation? Clin Cardiol. 2012 Jan;35 Suppl 1(Suppl 1):21-27.

16. Steinberg BA, Greiner MA, Hammill BG, Curtis LH, Benjamin EJ, Heckbert SR, Piccini JP. Contraindications to anticoagulation therapy and eligibility for novel anticoagulants in older patients with atrial fibrillation. Cardiovasc Ther. 2015 Aug;33(4):177-183.

17. Holmes DR, Reddy VY, Turi ZG, Doshi SK, Sievert H, Buchbinder $\mathrm{M}$, Mullin CM, Sick P; PROTECT AF Investigators. Percutaneous closure of the left atrial appendage versus warfarin therapy for prevention of stroke in patients with atrial fibrillation: a randomised non-inferiority trial. Lancet. 2009 Aug 15;374(9689):534-542.

18. Al-Kassou B, Omran H. Comparison of the Feasibility and Safety of First- versus Second-Generation AMPLATZER ${ }^{\text {TM }}$ Occluders for Left Atrial Appendage Closure. Biomed Res Int. 2017;2017:1519362.

19. Gilhofer TS, Saw J. Periprocedural Imaging for Left Atrial Appendage Closure: Computed Tomography, Transesophageal Echocardiography, and Intracardiac Echocardiography. Card Electrophysiol Clin. 2020 Mar;12(1):55-65.

20. Wang Y, Di Biase L, Horton RP, Nguyen T, Morhanty P, Natale A. Left atrial appendage studied by computed tomography to help planning for appendage closure device placement. J Cardiovasc Electrophysiol. 2010 Sep;21(9):973-982.

21. van Rosendael PJ, Katsanos S, van den Brink OW, Scholte AJ, Trines SA, Bax JJ, Schalij MJ, Marsan NA, Delgado V. Geometry of left atrial appendage assessed with multidetector- 
row computed tomography: implications for transcatheter closure devices. EuroIntervention. 2014 Jul;10(3):364-371.

22. Nakajima H, Seo Y, Ishizu T, Yamamoto M, Machino T, Harimura Y, Kawamura R, Sekiguchi Y, Tada H, Aonuma K. Analysis of the left atrial appendage by three-dimensional transesophageal echocardiography. Am J Cardiol. 2010 Sep 15;106(6):885-892.

23. Shah SJ, Bardo DM, Sugeng L, Weinert L, Lodato JA, Knight BP, Lopez JJ, Lang RM. Real-time three-dimensional transesophageal echocardiography of the left atrial appendage: initial experience in the clinical setting. $J$ Am Soc Echocardiogr. 2008 Dec;21(12):1362-1368.

24. Nucifora G, Faletra FF, Regoli F, Pasotti E, Pedrazzini G, Moccetti T, Auricchio A. Evaluation of the left atrial appendage with real-time 3-dimensional transesophageal echocardiography: implications for catheter-based left atrial appendage closure. Circ Cardiovasc Imaging. 2011 Sep;4(5):514-523.

25. Lang RM, Badano LP, Tsang W et al.; American Society of Echocardiography; European Association of Echocardiography. EAE/ASE recommendations for image acquisition and display using three-dimensional echocardiography. Eur Heart J Cardiovasc Imaging. 2012 Jan;13(1):1-46.

26. Bai W, Chen Z, Tang H, Wang H, Cheng W, Rao L. Assessment of the left atrial appendage structure and morphology: comparison of real-time three-dimensional transesophageal echocardiography and computed tomography. Int J Cardiovasc Imaging. 2017 May;33(5):623-633.

27. Goitein O, Fink N, Hay I, Di Segni E, Guetta V, Goitein D, Brodov Y, Konen E, Glikson M. Cardiac CT Angiography (CCTA) predicts left atrial appendage occluder device size and procedure outcome. Int J Cardiovasc Imaging. 2017 May;33(5):739-747.

28. Zhang L, Cong T, Liu A. Percutaneous closure of the left atrial appendage: The value of real time 3D transesophageal echocardiography and the intraoperative change in the size of the left atrial appendage. Echocardiography. 2019 Mar;36(3):537-545.

29. Whisenant B, Orford J. From Good to Great: Raising the Bar on LAA Closure With Pre-Procedure CT Planning. JACC Cardiovasc Interv. 2016 Nov 28;9(22):2341-2342.

30. Obasare E, Mainigi SK, Morris DL, Slipczuk L, Goykhman I, Friend E, Ziccardi MR, Pressman GS. CT based 3D printing is superior to transesophageal echocardiography for preprocedure planning in left atrial appendage device closure. Int J Cardiovasc Imaging. 2018 May;34(5):821-831.

31. Dutcher J, Schmidt W, Dahl P, Humbert J. Echopixel 3D Ct Vs. Transesophageal Echocardiography for Pre-Procedural Planning of Watchman Implantation. Journal of the American College of Cardiology. 2020;75(11):1206

32. Al-Kassou B, Tzikas A, Stock F, Neikes F, Völz A, Omran H. A comparison of two-dimensional and real-time $3 \mathrm{D}$ transoesophageal echocardiography and angiography for assessing the left atrial appendage anatomy for sizing a left atrial appendage occlusion system: impact of volume loading. EuroIntervention. 2017 Apr 20;12(17):2083-2091.

33. Freixa X, Chan JL, Tzikas A, Garceau P, Basmadjian A, Ibrahim R. The Amplatzer ${ }^{\mathrm{TM}}$ Cardiac Plug 2 for left atrial appendage occlusion: novel features and first-in-man experience. EuroIntervention. 2013 Jan 22;8(9):1094-1098.
34. Park JW, Bethencourt A, Sievert H, Santoro G, Meier B, Walsh $\mathrm{K}$, Lopez-Minguez JR, Meerkin D, Valdés M, Ormerod O, Leithäuser B. Left atrial appendage closure with Amplatzer cardiac plug in atrial fibrillation: initial European experience. Catheter Cardiovasc Interv. 2011 Apr 1;77(5):700-706.

35. Kappetein AP, Head SJ, Généreux P et al.; Valve Academic Research Consortium (VARC)-2. Updated standardized endpoint definitions for transcatheter aortic valve implantation: the Valve Academic Research Consortium-2 consensus document (VARC-2). Eur J Cardiothorac Surg. 2012 Nov;42(5):S45-60.

36. Tzikas A, Holmes DR Jr, Gafoor S, Ruiz CE, BlomströmLundqvist C, Diener HC, Cappato R, Kar S, Lee RJ, Byrne RA, Ibrahim R, Lakkireddy D, Soliman OI, Nabauer M, Schneider S, Brachmann J, Saver JL, Tiemann K, Sievert H, Camm AJ, Lewalter T. Percutaneous left atrial appendage occlusion: the Munich consensus document on definitions, endpoints, and data collection requirements for clinical studies. Europace. 2017 Jan;19(1):4-15.

37. Iriart X, Ciobotaru V, Martin C, Cochet H, Jalal Z, Thambo JB, Quessard A. Role of cardiac imaging and three-dimensional printing in percutaneous appendage closure. Arch Cardiovasc Dis. 2018 Jun-Jul;111(6-7):411-420.

38. Hur J, Kim YJ, Lee HJ, Ha JW, Heo JH, Choi EY, Shim CY, Kim TH, Nam JE, Choe KO, Choi BW. Left atrial appendage thrombi in stroke patients: detection with two-phase cardiac CT angiography versus transesophageal echocardiography. Radiology. 2009 Jun;251(3):683-690

39. Prakash R, Saw J. Imaging for percutaneous left atrial appendage closure. Catheter Cardiovasc Interv. 2018 Aug 1;92(2):437-450.

40. Korsholm K, Berti S, Iriart X, Saw J, Wang DD, Cochet H, Chow D, Clemente A, De Backer O, Møller Jensen J, NielsenKudsk JE. Expert Recommendations on Cardiac Computed Tomography for Planning Transcatheter Left Atrial Appendage Occlusion. JACC Cardiovasc Interv. 2020 Feb 10;13(3):277-292.

41. Tzikas A. Left Atrial Appendage Occlusion with Amplatzer Cardiac Plug and Amplatzer Amulet: a Clinical Trials Update. J Atr Fibrillation. 2017 Dec 31;10(4):1651.

42. Koskinas KC, Shakir S, Fankhauser Met et al. Predictors of Early (1-Week) Outcomes Following Left Atrial Appendage Closure With Amplatzer Devices. JACC Cardiovasc Interv. 2016 Jul 11;9(13):1374-1383.

43. Landmesser U, Schmidt B, Nielsen-Kudsk JE et al. Predictors of Early (1-Week) Outcomes Following Left Atrial Appendage Closure With Amplatzer Devices EuroIntervention. 2017 Sep 20;13(7):867-886.

44. Eng MH, Wang DD, Greenbaum AB, Gheewala N, Kupsky D, Aka T, Song T, Kendall BJ, Wyman J, Myers E, Forbes M, O'Neill WW. Prospective, randomized comparison of 3dimensional computed tomography guidance versus TEE data for left atrial appendage occlusion (PRO3DLAAO). Catheter Cardiovasc Interv. 2018 Aug 1;92(2):401-407.

45. Tzikas A, Shakir S, Gafoor S, Omran H et al. Left atrial appendage occlusion for stroke prevention in atrial fibrillation: multicentre experience with the AMPLATZER Cardiac Plug. EuroIntervention. 2016 Feb;11(10):1170-1179.

46. Omran H, Tzikas A, Sievert H, Stock F. A History of Percutaneous Left Atrial Appendage Occlusion with the PLAATO Device. Interv Cardiol Clin. 2018 Apr;7(2):137-142. 
(cc) (†)

This work is licensed under Creative

Commons Attribution 4.0 License

To Submit Your Article Click Here: Submit Manuscript

DOI:10.31579/2641-0419/145
Ready to submit your research? Choose Auctores and benefit from:

* fast, convenient online submission

* rigorous peer review by experienced research in your field

* rapid publication on acceptance

* authors retain copyrights

* unique DOI for all articles

* immediate, unrestricted online access

At Auctores, research is always in progress.

Learn more www.auctoresonline.org/journals/clinical-cardiology-andcardiovascular-interventions 